\title{
Learning Modules for the Statics Classroom
}

\author{
Anna Dollár, Paul S. Steif \\ Manufacturing and Mechanical Engineering Department \\ Miami University, Oxford, OH 45056 / \\ Department of Mechanical Engineering \\ Carnegie Mellon University, Pittsburgh, PA 15213
}

\section{Introduction}

Mechanical integrity, which remains an essential requirement for a vast array of technologies, new and traditional, is strongly rooted in the basic subjects of mechanics. The success of students in a wide range of courses in mechanical, civil, and manufacturing engineering is conditioned on the degree to which students have genuinely absorbed and "own" the ideas of elementary Statics. Statics instruction has been reasonably successful in teaching students to use the derived equations and to manipulate quantities mathematically. Students generally learn to solve problems in which the modeling is largely implied by standard symbols in problem diagrams. However, where Statics is finally relevant to engineering practice, instruction has been notably unsuccessful. Many faculty are disappointed with the extent to which students are able to use Statics in the analysis and design of real systems and structures which they confront in their subsequent education $[1,2]$, and later in their professional careers.

In our accompanying paper [3], we have argued that a new instructional approach needs to be adopted if students are to successfully apply Statics outside the classroom. We suggested that a root cause of student difficulties is a failure on the part of the student to relate the symbols of mechanics to what they represent. The meaning of the symbols of Statics is so elusive because the forces that relatively rigid, inanimate objects exert on one another, e.g., the forces between contacting parts of a machine, do not seem real to most students. Unfortunately, Statics instruction, as judged by virtually all textbooks, usually focuses primarily, if not exclusively, on the mechanics of machines and structures. Statics becomes purely a mathematical exercise when it deals with unreal forces.

As explained in more depth in [3], our new approach delays the treatment of machines and structures and instead focuses initially on situations in which the forces of interest are readily perceivable. Such forces include those that students exert with their own hands, as well as forces that are evident by virtue of the perceivable deformations and motions associated with them. We take advantage of people's strong intuitive sense of how to balance objects in various ways by hand and how to balance themselves. All the basic concepts of Statics, including forces, moments, couples, static equivalency, free body diagrams and equilibrium are all introduced in the 
context of perceivable forces. By doing so, we hope to address another significant shortcoming in typical Statics instruction: students' failures to use their physical intuition and experiences from every day life to anticipate and critique the results of mechanics.

\section{Instructional Innovations}

To implement this approach we have formed learning modules which link readily perceivable physical situations with the modeling or representational approaches of mechanics, using interactive, thought-provoking classroom methods. Our learning modules include classroom desktop experiments or demonstrations, PowerPoint Presentations and, often, Concept Questions. When the experiment involves an object, there is either a single copy of the object for the instructor to demonstrate in front of the class, or there are enough objects for every two or three students to share a copy. Students or instructor manipulate the objects - maintaining them in equilibrium, or creating their motion or deformation - in pursuit of various goals.

The instructor controls the PowerPoint Presentations which explore ideas introduced by the experiments and facilitate the transition from real objects to their models and representation with symbols. Each presentation depicts a physical object, how it can be held in equilibrium, deformed or otherwise manipulated under action of forces; it also serves to illustrate the free body diagrams corresponding to the configurations depicted. Students feel the real object under load (or see the instructor load it), see an illustration of the object under load, and finally discuss the corresponding free body diagrams. Some PowerPoint Presentations serve as a platform on which various examples can be rapidly constructed. The Presentations also provoke additional interaction among students, as well as between students and the instructor.

Many of the Presentations contain Concept Questions (CQ's), akin to Mazur's ConcepTests [4]. These are multiple-choice questions that assess student understanding of concepts, and which require little or no analysis. At the beginning of the semester, each student is given a set of colored index cards. When a question is posed (in a PowerPoint Presentation), with different answers coded in different colors, students vote for a particular answer by raising a colored card. When many students vote for the wrong answer, we invite them to argue the question with one another; this usually elicits rather vigorous discussion. In some cases, students are also encouraged to reflect on the question by manipulating the object. Students then vote again and any remaining discrepancies are discussed. This process stimulates students to think and argue with each other in class. Between the manipulation of objects, the verbal exchange and the eventually translation to symbolic representations, these methods can appeal to students with a variety of learning styles [5] and enable more students to succeed. 


\section{Description of Selected Modules with Examples of Power Point Slides}

1. Moments and couples in 3-D

Moments in 3-D are explained first using a box that can spin about three rods piercing it parallel to its three color-coded edges. The instructor applies forces at various points which cause rotations of the box about different axes. Students indicate with color cards what the moment arm is in each case.

Next, the Power Point slide presented at fig. 1 is used. The instructor picks axes and force vectors from the "tools" and applies them to the box. Students again vote with color cards. The two activities, even though similar one to the other, are meant to help students make a transition from real objects and forces that can be readily perceived to their representations. Fig. 2 shows an example of a CQ that students are asked afterwards.

We address the concept of equivalent couples in a similar manner. We use an object first, then a Power Point slide as a teaching tool, and then we ask students a series of CQs. We use two examples: the box rotating about different axes (fig. 3) and a deformable bar (fig. 4) which is pierced by two rods in a cross pattern and loaded with pairs of forces creating twisting or bending of the bar. The rotation of the box is seen to be the same when pairs of forces are applied in different directions; the deformation of the bar is seen to be the same when pairs of forces are applied in different directions to the cross.

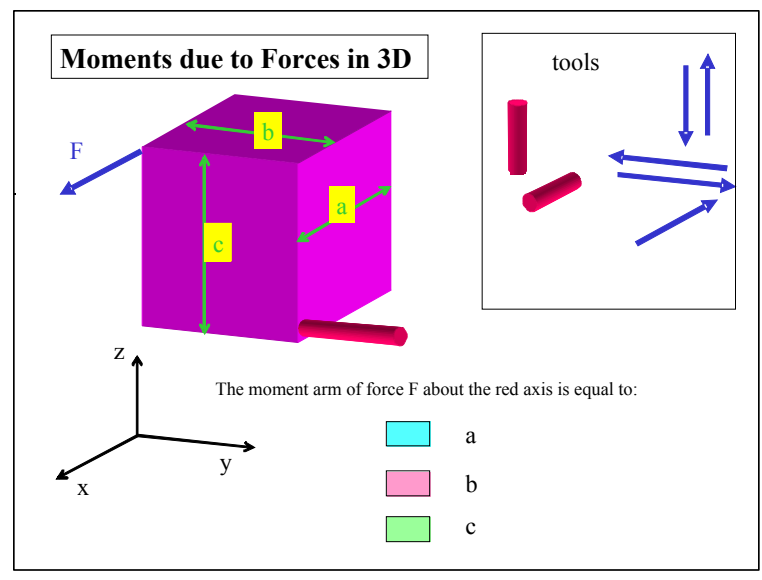

Fig. 1

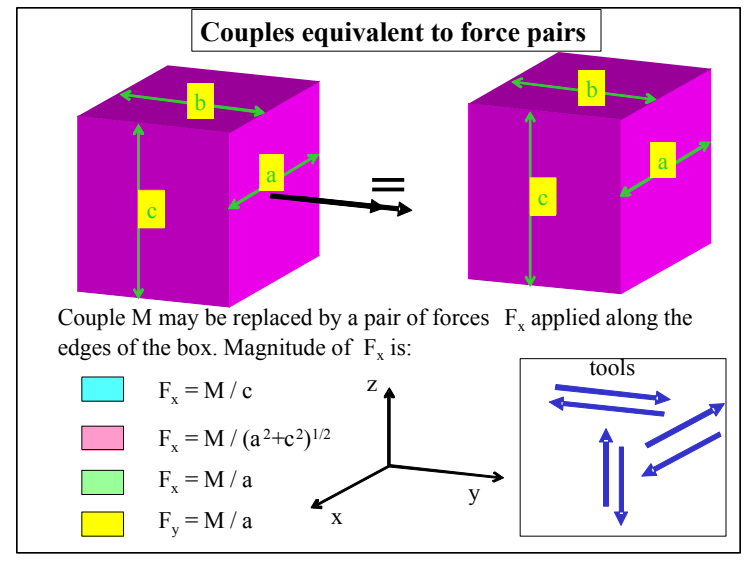

Fig. 3

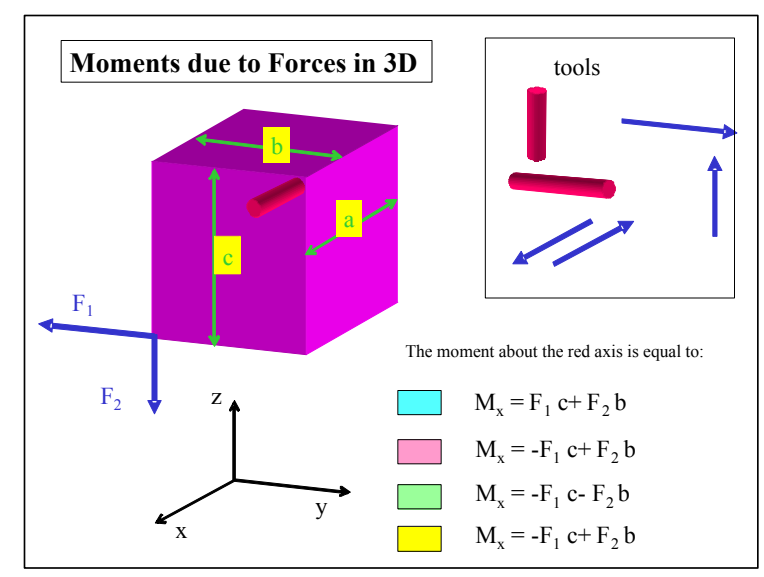

Fig. 2

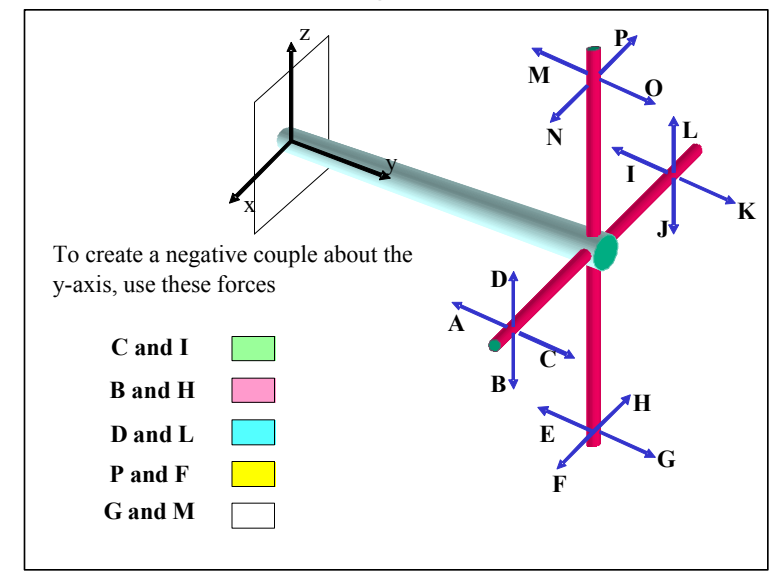

Fig. 4

Proceedings of the 2003 American Society for Engineering Education Annual Conference \& Exposition Copyright (C) 2003, American Society for Engineering Education 


\section{Balancing human body}

Students balance their own bodies and answer questions to determine the forces and couples keeping a person in balance. We start by analyzing simple situations of a person standing on two feet and leaning forward and backward, then progress to modeling a person pushing the wall with two hands (fig. 5, 6), and finally we analyze a 3-D problem of a person standing on one foot and pushing against a wall with the opposite hand (fig. 7-10). Equilibrium of forces and moments about various axes are discussed.

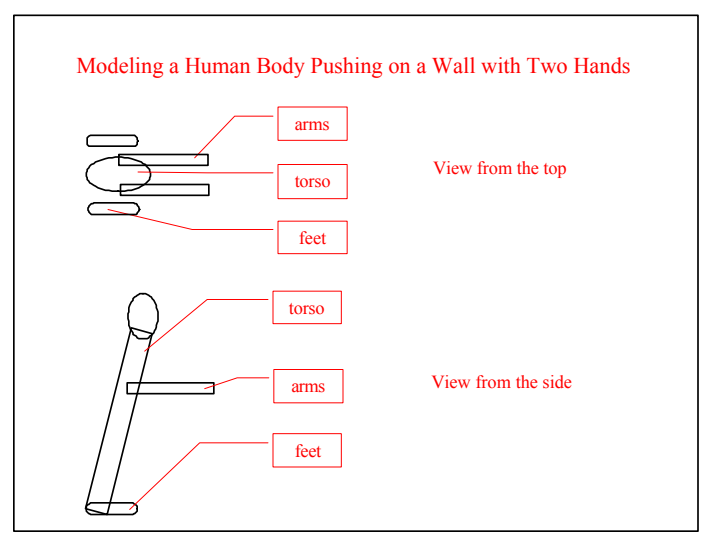

Fig. 5

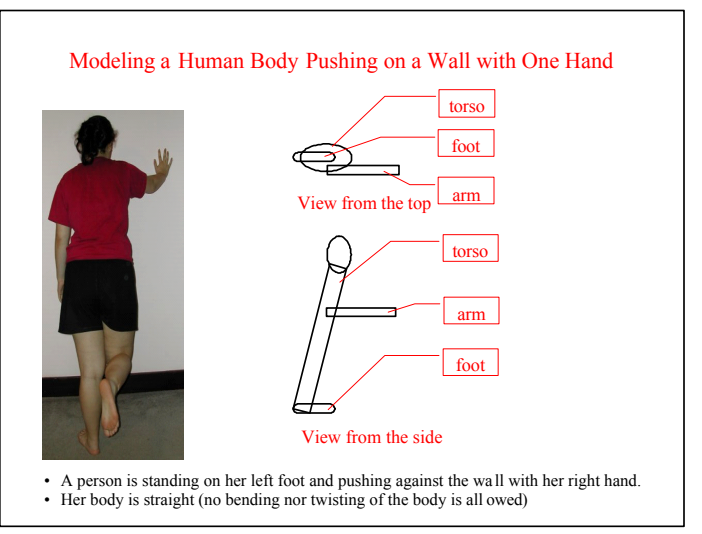

Fig. 7

We have determined that only $\left.\Sigma M\right|_{2}=0$ is not satisfied $Y$ there needs to be an additional couple to keep the body in balance.

What is the direction of the couple that is missing on this FBD?

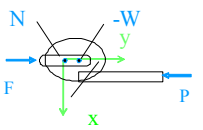

This couple is exerted by:

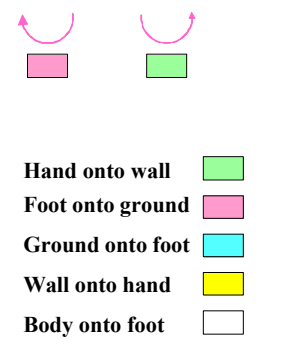

Fig. 9

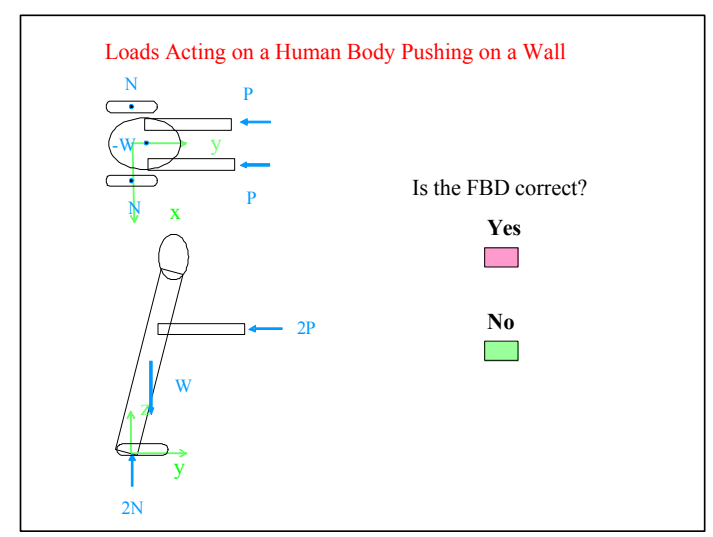

Fig. 6

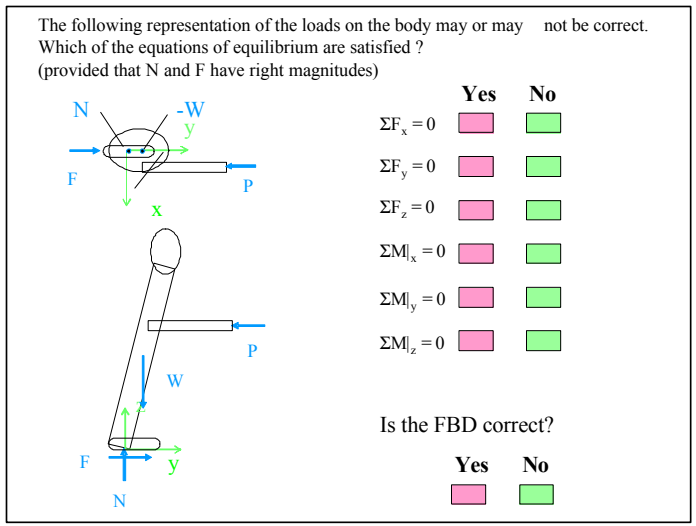

Fig. 8

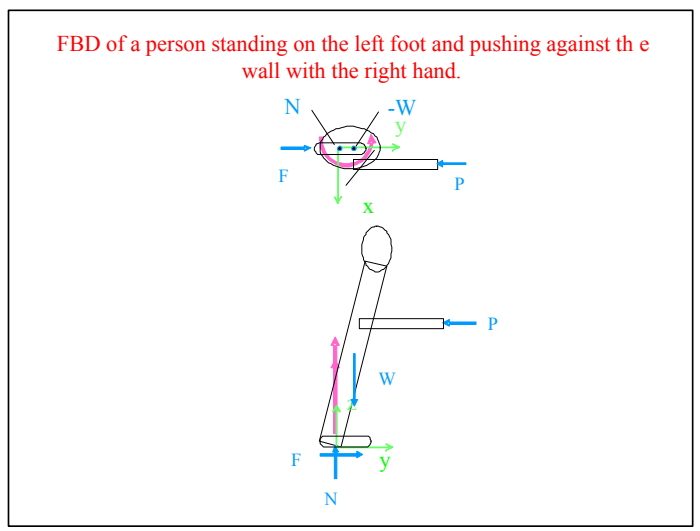

Fig. 10

Proceedings of the 2003 American Society for Engineering Education Annual Conference \& Exposition Copyright (C) 2003, American Society for Engineering Education 


\section{Moving a force to a new line of action}

We use three activities to illustrate this concept. In each we demonstrate that equivalent forcecouple systems have the same effect on the body - the same motion, balance, or deformation.

In the first example (fig. 11) we use a bar pierced by two skewers lying in a horizontal plane to demonstrate that the motion produced by applying one force, and the motion produced by applying a force with the same magnitude and direction elsewhere together with a couple are the same. We also demonstrate that the couple may be applied anywhere on the bar.

In the second activity we ask students to maintain a bar in equilibrium in the vertical plane (fig.12). The bar is balanced at its center with one force, and then with a rubber band off center and a couple. The couple may be applied by a nut driver or by the pair of forces (the effect being the same as evidenced by the same stretch of the rubber band). The FBDs are then discussed and couples are quantified.

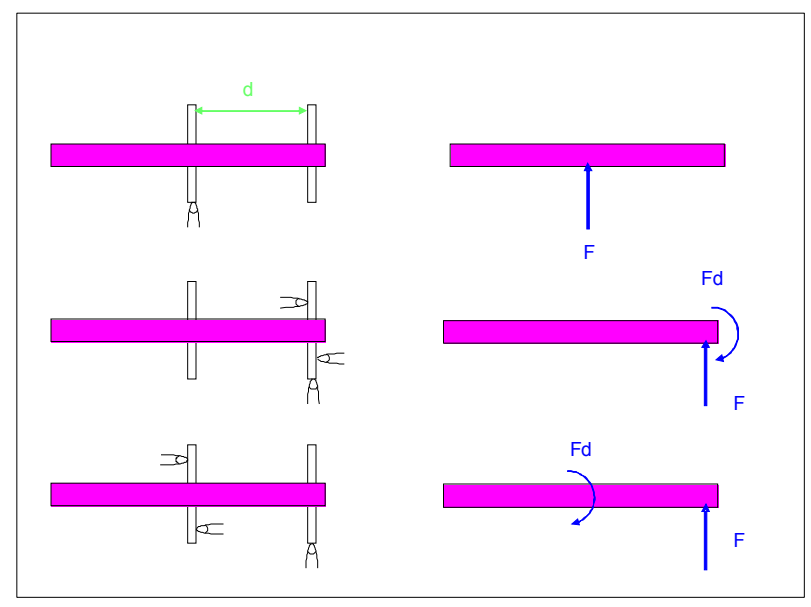

Fig. 11

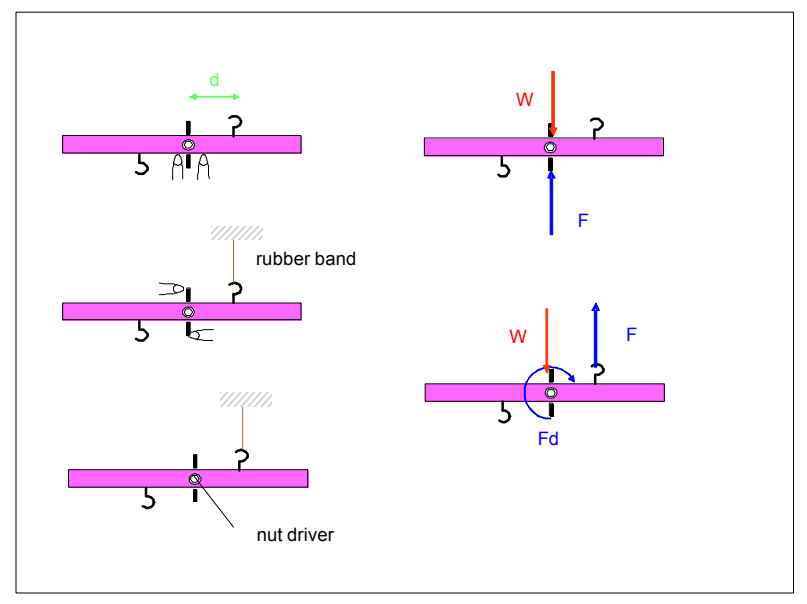

Fig. 12

In the third activity a deformable bar, which is pierced by two rods in a cross pattern, is loaded with a single force at one arm of the cross (fig.13). The deformation of the bar is seen to be the same as when a force and a couple are applied directly to the bar.

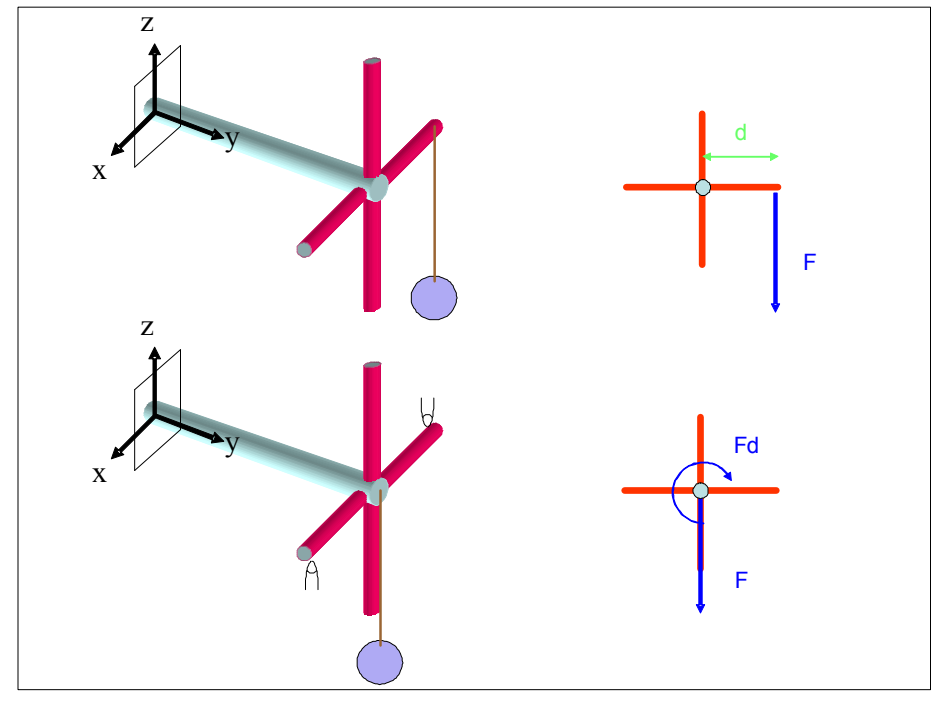

Fig. 13

Proceedings of the 2003 American Society for Engineering Education Annual Conference \& Exposition Copyright $\odot$ 2003, American Society for Engineering Education 
4. Balancing a 3-D body with forces applied by fingers and couples applied by nut driver. Students consider equilibrium of an L-shaped member which may be kept in balance by fingers placed underneath it and with a nut driver that supplies a couple. Prior to experimenting with the object students are asked CQ's pertaining to its equilibrium (fig. 14-18). Many students answer them incorrectly. Then they are encouraged to manipulate the object using their fingers and a nut driver and are asked the same questions again. This provides an opportunity for them to reexamine their answers based on applying equilibrium equations and experimenting with the physical object. The abstract concept of a couple seems to become more meaningful after this discussion and most of the students answer the CQ's successfully.

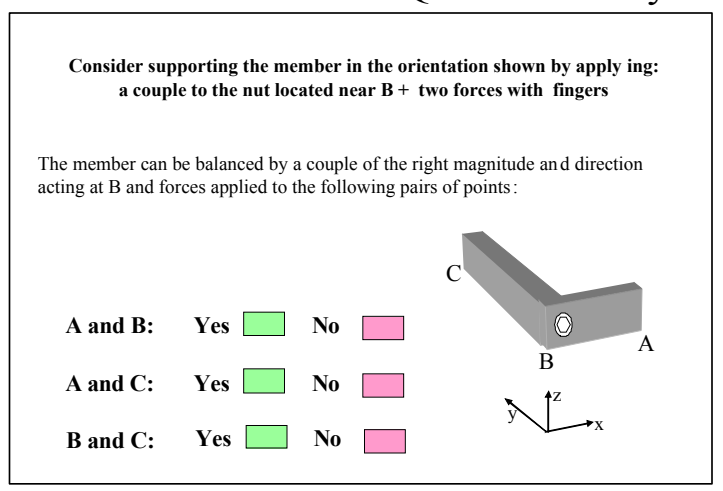

Fig. 14

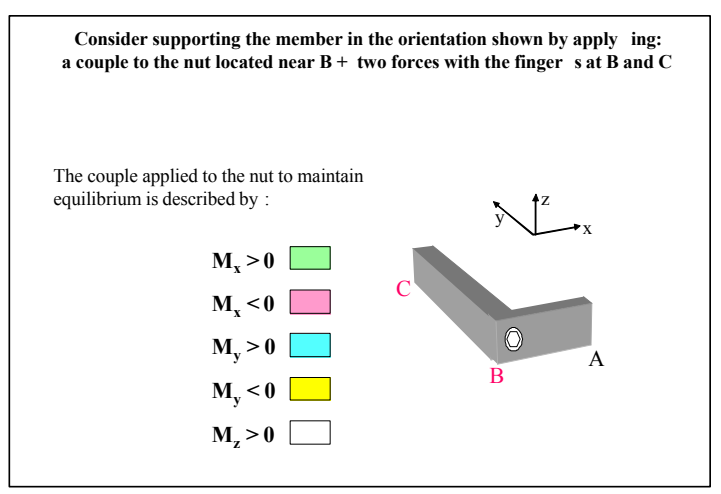

Fig. 15

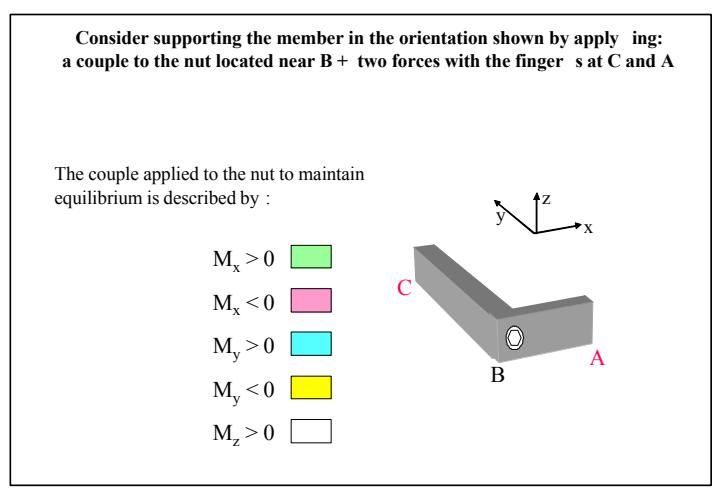

Fig. 17

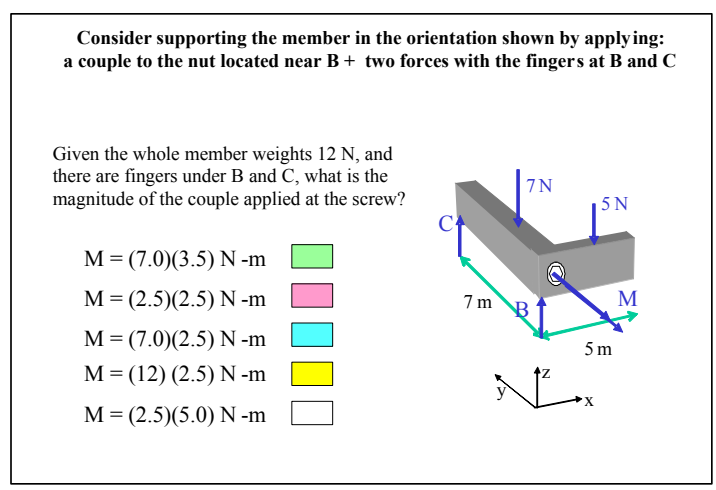

Fig. 16

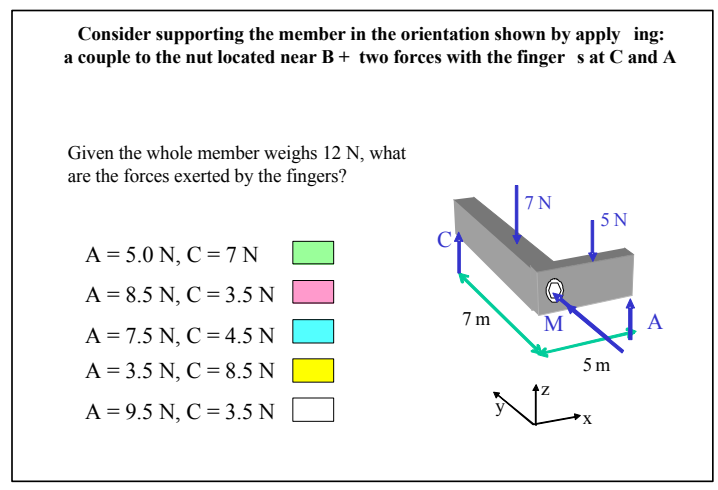

Fig. 18

Proceedings of the 2003 American Society for Engineering Education Annual Conference \& Exposition Copyright $@$ 2003, American Society for Engineering Education 


\section{Student Response to Initial Use of Learning Modules}

Approximately ten learning modules were implemented in our classrooms over the course of a semester long Statics course of 100 and 30 students, respectively. At the end of the semester, students were surveyed regarding the effectiveness of the activities. The generally positive response reinforced a range of other feedback during the course indicating that the hands-on activities combined with PowerPoint Presentations and Concept Questions were indeed effective. The survey was also helpful in identifying activities that needed to be improved.

Acknowledgements: Support by the Department of Mechanical Engineering at Carnegie Mellon University and by Miami University Department of Manufacturing and Mechanical Engineering is gratefully acknowledged.

\section{Bibliographic Information}

1. Harris, T.A. and Jacobs, H.R., 1995, J. Eng. Educ., Vol. 84, p. 343.

2. National Research Council Report, 1999, Transforming Undergraduate Education in Science, Mathematics, Engineering, and Technology, National Academy Press, Washington D.C.

3. A. Dollár, P. S. Steif, A New Approach to Teaching and Learning Statics, Proceedings of the 2003 American Society for Engineering Education Annual Conference \& Exposition 2003, Nashville

4. E. Mazur, 1997, Peer Instruction, Prentice Hall, New Jersey.

5. Bransford, J. and Brown, A., How People Learn, National Academy Press, Washing D.C.

\section{Biographical Information}

\section{Anna Dollár}

Associate Professor, Department of Manufacturing and Mechan ical Engineering, Miami University, Oxford, Oh Degrees: Ph.D., M.S., Krakow University of Technology, Poland.

Research area: solid mechanics and engineering education.

\section{PAUL S.STEIF}

Professor, Department of Mechanical Engineering, Carnegie Mellon University, Pittsburgh, Pa

Degrees: Sc. B. 1979, Brown University; M.S. 1980, Ph.D. 1982, Harvard University.

Research area: solid mechanics and engineering education. 